\title{
Inequality in mortality decreases with age: Evidence from developing countries using census data
}

\author{
Rubén Castro ${ }^{1}$ \\ Eduardo Fajnzylber \\ Andrés Fortunato
}

\begin{abstract}
With few exceptions, studies consistently find that mortality rate ratios between the highest and lowest socioeconomic status (SES) groups decline with age. This un-intuitive pattern is relevant for policy and research, but it has seldom been explored in the populations of developing countries. In this study, we use SES groups of equal relative size to compare mortality rate ratios by age for eight samples in the Integrated Public Use Microdata Series (IPUMS) that contain mortality and household assets data (El Salvador 1992, Rwanda 2002, Senegal 2002, Sierra Leone 2004, Uganda 2002, Malawi 2008, Brazil 2010, and Zambia 2010). Seven samples show the same results as those found in developed countries: SES morality rate ratios consistently decrease with age.
\end{abstract}

Keywords: inequality, mortality, aging, census data, developing countries.

\section{Résumé}

Quelques exceptions mises à part, la plupart des études montrent de manière consistante que le ratio de taux de mortalité entre les groupes aux statuts socio-économiques (SSE) les plus élevés et les plus basses diminue avec l'âge. Ce constat pas intuitif est d'une grande importance pour la politique et la recherche, mais il n'a pourtant été que rarement été explore au sein des populations de pays en développement. Dans cette étude, nous utilisons des SSE de taille relative égales pour comparer le ratio de taux de mortalité par âge per huit échantillons de l'"Integrated Public Use Microdata Series" (IPUMS) contenant des données de mortalité ainsi que des informations sur les actifs immobiliers des ménages (Salvador 1992, Rwanda 2002, Sénégal 2002, Sierra Leone 2004, Ouganda 2002, Malawi 2008, Brésil 2010, et Zambie 2010). Dans sept échantillons les résultats sont les mêmes : le ratio de mortalité relatif au SSE diminue de manière consistante avec l'âge.

Mots-clés : inégalité, la mortalité, vieillissement, données de recensement, les pays en voie de développement.

\section{Introduction}

Broadly speaking, mortality inequality refers to the idea of well-being inequality, since mortality is a key indicator of a population's health. However, the relation between mortality and socio-economic inequality has proven to be a complicated one. While intuition suggests that higher income inequality should be linked with higher mortality, the scientific evidence is at the least inconclusive, at the most controversial (Erreygers and Van Ourti 2011; Lynch et al.. 2001, 2004; Rowlingson 2011; Wagstaff et al. 1991; Wilkinson and Pickett 2006). Moreover, mortality inequality, i.e., the differential mortality experienced between a high and a low socio-economic group, is equally visible in countries with low income inequality, such as Finland, Sweden, and Norway (Mackenbach et al. 1997, 2003).

The mortality rate ratio (between the lowest and highest socio-economic group) clearly decreases with the age group of the population (Beckett 2000; Lynch et al. 2001). This is certainly a challenging result. Mortality is fairly measurable and a well-known index of cumulative health; it is intuitive to expect that the ratios would

1. Corresponding author: Rubén Castro, Public Policy Institute, Universidad Diego Portales, Santiago, Chile; email: ruben.castro@udp.cl. Eduardo Fajnzylber, Escuela de Gobierno, Universidad Adolfo Ibañez, Santiago; Andrés Fortunato, Universidad de Chile, Santiago. 
grow instead of shrink across age, because the widely accepted idea of a cumulative economic advantage across the life cycle suggests the idea of a cumulative advantage in health.

Many articles thus far have explored this pattern. Some of them point to the role of selective mortality, which could "wipe out" the ratio, as the weakest individuals die before old age (Dupre 2007; Willson et al. 2007); however, this has been repeatedly found to not be enough to explain the decreasing ratio (Beckett 2000; Herd 2006; Kim and Durden 2007). Other articles deal with cohort effects (Herd 2006; House et al. 2005; Lynch 2003), where increases in ratios across time first affect the younger population, which explains why their ratios are higher. Yet another explanation is a changing mix of population across age, which starts with healthy individuals, where ratios are large, and ends with mostly unhealthy individuals, where ratios are somewhat smaller (Hoffmann 2005).

None of these mechanisms, however, seem to fully explain the pattern of a decreasing mortality ratio with age (Herd 2006; Kim and Durden 2007; Mirowsky and Ross 2008). The evidence of this pattern arises from both cross-sectional and cohort-specific analysis (Marmot and Shipley 1996), and is found along several socioeconomic status (SES) dimensions, such as education, race, income, native/foreign status (Singh and Hiatt 2006; Singh and Siahpush 2001), occupational status (Avendano and Glymour 2008), and combinations of different measures (Martelin 1994). The decreasing ratio has been found in several developed countries, such as Finland (Martikainen 2001), England (Marmot and Shipley 1996; McMunn et al. 2009), Australia (Mishraa et al. 2004; Turrell and Mathers 2001), the United States (Avendano and Glymour 2008; House et al. 2005; McDonough et al. 1997), and a broad range of European countries (Huisman et al. 2004). The ratio is also found in the analysis of specific causes of mortality, such as lung cancer in ten European populations (Mackenbach et al. 2004) and ischemic heart disease mortality in ten Western European populations during the 1990s (Avendano et al. 2006). Moreover, the predictive power of income inequality on mortality has been found to be larger for young segments of populations (Ross et al. 2000). Beyond mortality, self-rated health and functional limitations in twentytwo European countries show the same pattern (Subramanian and Kawachi 2004).

Some studies have found no evidence of such a correlation, such as among men in England and Wales (Chandola et al. 2007; Huisman et al. 2004), and females in Belgium, Switzerland, and Austria (Huisman et al. 2004). Regarding self-reported health, one study of the Canadian population (Prus 2007) found an increasing ratio with age.

There is no clear evidence on this association in any developing country. Because mortality is an infrequent event among young people and adults, these types of studies require costly data, so studies on mortality inequality tends to focus on child mortality (Brockerhoff and Hewett 2000; Sastry 2004; Victora et al. 2003; Wagstaff 2000) and maternal mortality (Ronsmans and Graham 2006; Say and Raine 2007; Stokoe 1991). Developing countries have differing public health services and social security nets, and exploring whether the pattern holds among them could shed some light on understanding the pattern itself.

This study adds to the literature by analyzing data from developing countries, available in a few samples of census data on the Integrated Public Use Microdata Series data base (IPUMS 2015), that (a) contain additional files regarding mortality; and (b) have enough information to build a consistent wealth index, based on household goods, to be used as a relative SES measure that is fairly comparable across countries. The results show that seven out of eight samples that contain the required data perform consistently the same as the ones in many developed societies: mortality rate ratios decrease across the age groups of the population.

\section{Methodology and data}

This study uses census data to compute relative SES of equal size, and mortality rate ratios by SES; then an individual regression analysis is used to test the statistical significance of the age effect on the ratios.

\section{Data}

The Integrated Public Use Microdata Series collects several samples of census data around the world. It also includes additional files regarding fertility, migration and mortality, for those censuses that collect such information. 
Castro et al.: Inequality in mortality decreases with age: Evidence from developing countries using census data

This study covers eight developing countries: El Salvador 1992, Rwanda 2002, Senegal 2002, Uganda 2002, Sierra Leone 2004, Malawi 2008, Brazil 2010, and Zambia 2010. Their census data is available in the Integrated Public Use Microdata Series, and contains mortality data (IPUMS 2015) and sufficient information to build up a wealth index, based on household data, to be used as SES measure. IPUMS, from now on, refers to this data.

\section{SES measure}

Studies use different measures of SES, including education, income, wealth, occupation status, and even race and citizenship status. All those variables have advantages and disadvantages. Education is the salient measure of SES in this literature, but has some relevant disadvantages: it is not a standard measure across countries, which is central in a field of research that focuses much attention on aggregate level analysis, and does not allow for a comparison across cohorts-when, as is the case of many developing countries, the education profiles are changing rapidly over time. Finally, because education is not fixed across life, it is a complex measure to use across age groups, especially among the young population.

One key point regarding the selection of a SES measure is the kind of data available. Mortality rates are very low and hence difficult to measure among the young population. Complete vital records are very helpful to estimate them, but this kind of data usually includes little socio-economic information.

In this study, a wealth index is estimated and used to rank households. The wealth index is built upon asset ownership information available in the IPUMS, using the methodology described in the Demographic and Heath Surveys Wealth Index (DHS 2004), Vyass and Kumaranayake (2006), Córdova (2009), and Lovatón et al. (2011) to dichotomize all variables and compute the wealth index from a principal component analysis that places individual households on a continuous scale of relative wealth. Because the availability of variables change from sample to sample, this study includes only samples with at least six variables in the durable asset categories (availability of TV, cars, VCR, radio, computer, washer, freezer, and refrigerator) and utility categories (electricity, water supply, sewage, trash disposal, gas for cooking, hot water, heat, air conditioning, telephone, cellphone, internet, and email) combined, and at least three variables in dwelling characteristics (room quantity, bathroom quantity, building material of floor, walls, and roof, and availability of kitchen, toilet, and/or bath) and ownership of the house categories combined.

\section{Mortality rate and mortality rate ratios}

Mortality data in IPUMS consists of additional files with "deaths in the household in the previous 12 months." The mortality rate in this study is constructed as the number of such deaths over the number of total persons in the household at the moment of the census interview. This measure of mortality is not entirely correct, since the denominator should reflect the person's years exposed to the risk of dying in the same time interval as the numerator (previous 12 months). However, this ratio might provide reasonable accuracy, because the time span is relatively short.

In this study, 10 deciles of the wealth index are defined as socio-economic groups, independently in each survey. With this index, 30/30 ratios of mortality rates are computed (mortality rate among the 30 per cent with lowest SES over mortality in the highest 30 per cent).

Therefore, this study uses mortality rate ratios between socio-economic groups as a measure of health inequality. This simple measure is commonly used in the related literature. Another option is to use the absolute rather than the relative difference between SES groups. This study takes a relative approach, following the idea of inequality as a phenomenon that emerges from the relative status among individuals. An absolute approach, however, can be useful for public health studies where the occurrence of deaths itself is a central matter. Now, the 30/30 ratio, used in this study for simplicity, could be replaced with the "concentration index"; this index uses data from the entire distribution of SES groups, but this study, using more than two or three groups only adds instability in the computations of young morality rates. 


\section{Results}

The descriptive statistics of aggregate data in Table 1 show age-interval and sex-specific mortality rates by country for aggregate data. The $90+$ interval shows unstable mortality rate ratios across samples, and therefore conclusions for this age interval should be made with caution.

Table 1. Descriptive statistics of aggregate data (population and death rates)

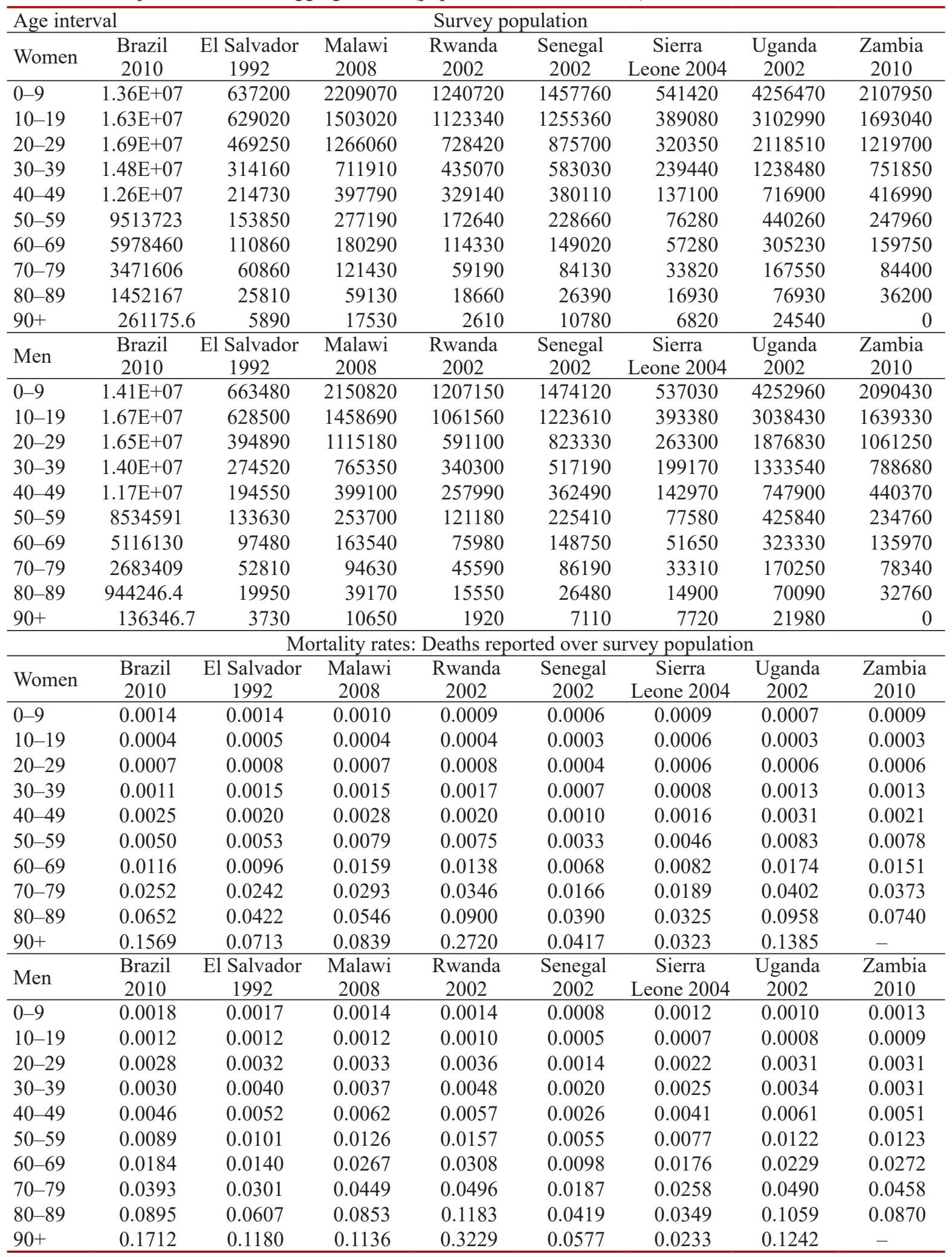

Source: Authors' calculations, based on IPUMS survey data. 
The mortality rate ratios by age and country in Figure 1 show that ratios decrease with age for seven of the eight countries. The pattern is clearly visible in six of the eight cases, plus in El Salvador 1992, the only pre-2000 sample in IPUMS; in this case, the very young population (0-19 years old) shows a surprising less-than-one ratio, and after that age, the declining ratio is visible. The pattern is not visible in Uganda 2002. Figure 1 also shows that ratios are in general higher among men than women, as is usual in the relevant literature.

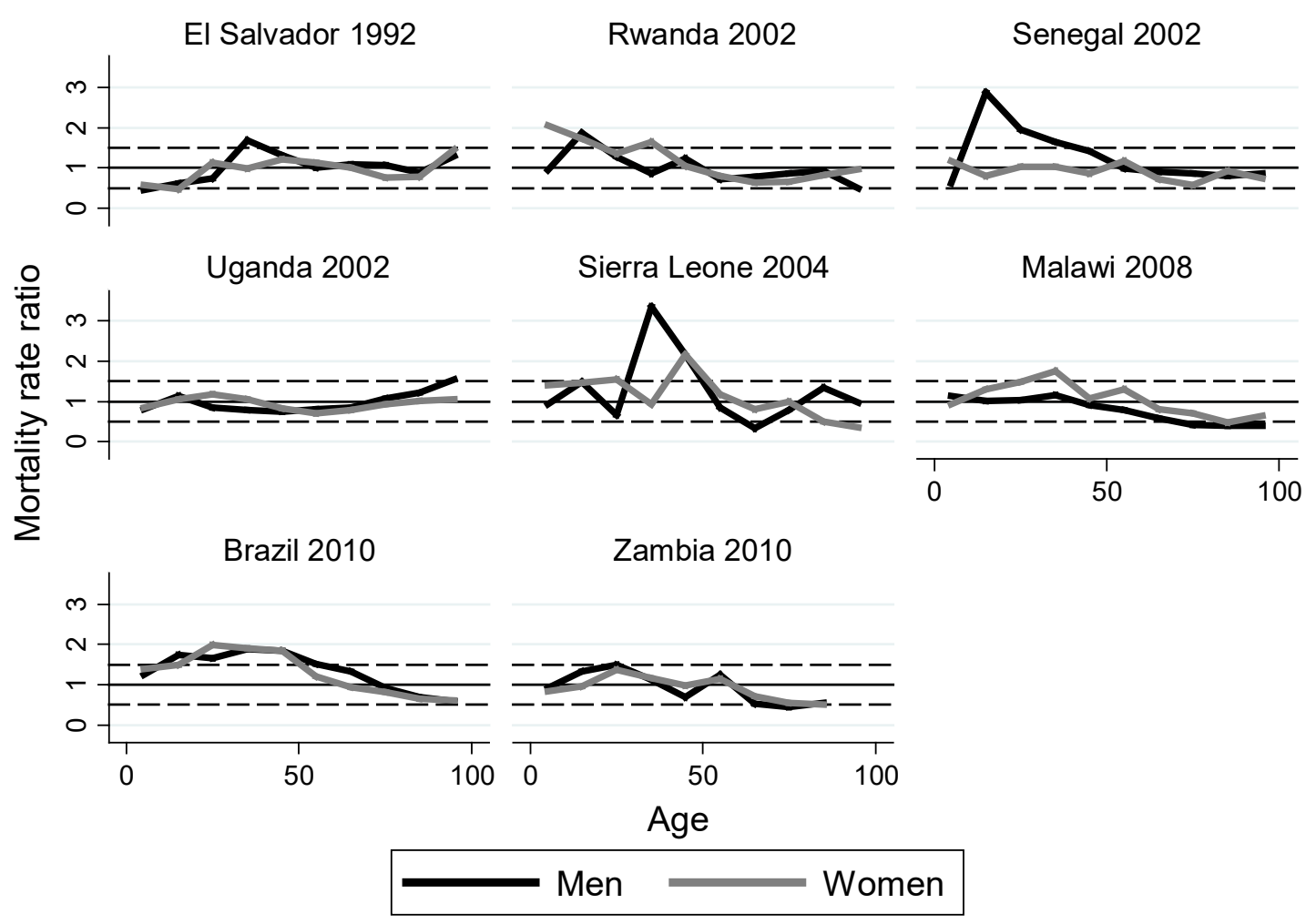

Figure 1. IPUMS: Mortality rate ratio by SES.

Source: Authors' calculations, based on IPUMS survey data.

The sample with the strongest ratios is Brazil 2010. Lower-than-one ratios, meaning that low relative-SES group comes with lower mortality, are found among groups of very old-aged individuals.

Using the same data as in Figure 1, Table 2 shows the ordinary least squares estimators from a linear regression of sex and age group over the mortality rate ratios, adding country fix effects (with Brazil as the excluded category). Every country fix effect appears with a negative sign, signaling Brazil as the country with the strongest ratios, as previously stated. The age group appears significant and with a negative sign, just as seen in Figure 1.

Table 2. Linear regression results for the mortality rate ratio using aggregate data

\begin{tabular}{ll}
\hline Regressor & \multicolumn{2}{c}{ Coefficient } \\
\hline Age group & $-0.0063(0.000)$ \\
Women & $-0.0352(0.597)$ \\
El Salvador 1992 & $-0.3323(0.011)$ \\
Malawi 2008 & $-0.3953(0.000)$ \\
Ruwanda 2002 & $-0.2333(0.038)$ \\
Senegal 2002 & $-0.2160(0.113)$ \\
Sierra Leone 2004 & $-0.0984(0.566)$ \\
Uganda 2002 & $-0.3484(0.002)$ \\
Zambia 2010 & $-0.4276(0.000)$ \\
Constant & $1.6461(0.000)$ \\
\hline
\end{tabular}

Source: Authors' calculations, based on

IPUMS survey data. P-values in parenthesis. 
To replicate the analysis but using individual-level data, the same variable in the aggregated analysis (deaths among members of the household in the last 12 months) is used to compute a dichotomous "death last year" variable, being zero for all living members and one for every recently dead member of the household. Table 4 displays marginal effect results of a probit regression of "death last year" on covariates using this data (descriptive data can be found in Table 3); the first income decile corresponds to the richest population.

Table 3. Descriptive statistics of individual-level data

\begin{tabular}{lrrrrrr}
\hline & \multicolumn{2}{c}{ Women } & \multicolumn{2}{c}{ Men } & \multicolumn{2}{c}{ Total population } \\
\cline { 2 - 7 } Death last year: & \multicolumn{1}{c}{ Yes } & \multicolumn{1}{c}{ No } & \multicolumn{1}{c}{ Yes } & \multicolumn{1}{c}{ No } & \multicolumn{1}{c}{ Yes } & No \\
\hline Brazil 2010 & 47,308 & 234 & 46,499 & 320 & 93,807 & 554 \\
El Salvador 1992 & 2,610 & 15 & 2,541 & 14 & 5,151 & 29 \\
Malawi 2008 & 6,828 & 64 & 6,534 & 67 & 13,362 & 131 \\
Rwanda 2002 & 4,283 & 34 & 3,735 & 33 & 8,018 & 67 \\
Senegal 2002 & 5,015 & 57 & 4,900 & 45 & 9,915 & 102 \\
Sierra Leone 2004 & 1,795 & 43 & 1,796 & 28 & 3,591 & 71 \\
Uganda 2002 & 12,329 & 147 & 12,204 & 133 & 24,533 & 280 \\
Zambia 2010 & 6,796 & 99 & 6,424 & 93 & 13,220 & 192 \\
\hline Total & 86,964 & 693 & 84,633 & 733 & 171,597 & 1,426 \\
\hline Sol
\end{tabular}

Source: Authors' calculations, based on IPUMS survey data.

Table 4. Probit results for "death last year" using micro level data

\begin{tabular}{lr}
\hline Regressor & \multicolumn{1}{c}{ Coefficient } \\
\hline Women & $-0.0897(0.000)$ \\
Age & $0.0190(0.000)$ \\
Age $^{2}$ & $0.0000(0.000)$ \\
Decile & $0.0429(0.000)$ \\
Age*decil & $-0.0006(0.002)$ \\
El Salvador 1992 & $0.1089(0.120)$ \\
Malawi 2008 & $0.3703(0.000)$ \\
Ruwanda 2002 & $0.3642(0.000)$ \\
Senegal 2002 & $0.3882(0.000)$ \\
Sierra Leone 2004 & $0.6307(0.000)$ \\
Uganda 2002 & $0.4836(0.000)$ \\
Zambia 2010 & $0.5654(0.000)$ \\
Constant & $-3.3204(0.000)$ \\
\hline Source: Authors' calculations, based on IPUMS \\
survey data. P-values in parenthesis.
\end{tabular}

The results show that "death last year" increases by 4.29 per cent as the wealth index decreases by one decile, and is slightly higher for men than woman (about 8.97 per cent) as is found in the related literature and is shown by the aggregate data. All countries show higher probabilities of death than Brazil 2010 (the excluded category), with Sierra Leone 2004 being the highest at 63.07 per cent.

The variable of interest here is the interaction between age and income decile. Both variables appear significantly and positively correlated with the probability of having died last year, just as is expected, but the interaction has a negative significant effect ( -0.06 per cent), suggesting that the socio-economic association with higher mortality decreases with age.

\section{Discussion}

This article contributes to the knowledge of the mortality rate ratio between socio-economic groups across the life cycle. Policies that are designed to alleviate well-being inequalities might consider focusing on age groups, 
where this gap is larger. Research projects exploring the link between economic resources and inequality could study the mechanisms that cohorts "use" to attenuate this impact across the life cycle.

This article demonstrates that the ratio of mortality by relative-SES ratio, which has been found to decrease with age in many but not all developed countries, also decreases with age in the population of seven of the eight developing countries observed here, and therefore reinforces the idea that this pattern might be observable in most countries and times.

This descriptive study has clear limitations, as the main result is based on simple regression and its sample of countries is not a probabilistic sample. Additionally, any choice of SES measure implies some disadvantage, as there is wide arrange of SES measures in the literature, including education, income, wealth, work status, race, immigrant status, home ownership, and others (although the main pattern of a decreasing mortality rate across age is visible with many or all of these SES measures). Additionally, mortality census data may be underreported (Hill and Stanton 2011; Say and Raine 2007; Stokoe 1991; Timeaus 1991); if articulated with age at death, this might introduce bias in our analysis.

Mortality selection, cohort effects, and period effects might be partially responsible for the age pattern of mortality ratios, but within the cross-sectional census data used in this study, it is very difficult to explore in detail the relative contribution of each of them. A review of the literature, however, shows that they do not explain the pattern entirely (Herd 2006; Kim and Durden 2007; McMunn et al. 2009), and there is no evident pattern that could be informative to test among developing countries. In general, much remains to be done regarding the understanding of this phenomenon.

\section{References}

Avendano, M., and Glymour, M.M. 2008. Stroke disparities in older Americans: Is wealth a more powerful indicator of risk than income and education? Stroke 39(5):1533-40.

Avendano, M., A.E. Kunst, M. Huisman, F.V. Lenthe, M. Bopp, E. Regidor, [...], and C. Borrell. 2006. Socioeconomic status and ischaemic heart disease mortality in 10 western European populations during the 1990s. Heart 92(4):461-67.

Beckett, M. 2000. Converging health inequalities in later life: An artifact of mortality selection? Journal of Health and Social Behavior 41(1):106-19.

Brockerhoff, M., and P. Hewett. 2000. Inequality of child mortality among ethnic groups in sub-Saharan Africa. Bulletin of the World Health Organization 78(1):30-41.

Chandola, T., J. Ferrie, A. Sacker, and M. Marmot. 2007. Social inequalities in self-reported health in early old age: Follow-up of prospective cohort study. The BMJ 334(7601):990, https://doi.org/10.1136/bmj.39167.439792.55.

Córdova, A. 2009. Methodological Note: Measuring relative wealth using Household Asset Indicators. AmericasBarometer Insights (Latin American Public Opinion Project) 6.

DHS Wealth Index. 2004; Available at http://www.dhsprogram.com/publications/publication-cr6-comparativereports.cfm.

Dupre, M.E. 2007. Educational differences in age-related patterns of disease: Reconsidering the cumulative disadvantage and age-as-leveler hypotheses. Journal of Health and Social Behavior 48(1):1-15.

Erreygers, G., and T. Van Ourti. 2011. Measuring socioeconomic inequality in health, health care and health financing by means of rank-dependent indices: A recipe for good practice. Journal of Health Economics 30(4):685-94.

Herd, P. 2006. Do functional health inequalities decrease in old age? Educational status and functional decline among the 1931-1941 birth cohort. Research on Aging 28(3):375-92. 
Hill, K., and C. Stanton. 2011. Measuring maternal mortality through the census: Rapier or bludgeon? Journal of Population Research 28(1):31-47.

House, J.S., P.M. Lantz, and P. Herd. 2005. Continuity and change in the social stratification of aging and health over the life course: evidence from a nationally representative longitudinal study from 1986 to 2001/2002 (Americans' Changing Lives Study). The Journals of Gerontology Series B: Psychological Sciences and Social Sciences 60(Special Issue 2):S15-S26.

Hoffmann, R. 2005. Do socioeconomic mortality differences decrease with rising age? Demographic Research 13(2):35-62.

Huisman, M., A.E. Kunst, O. Andersen, M. Bopp, J.K. Borgan, C. Borrell, [...], and S. Gadeyne. 2004. Socioeconomic inequalities in mortality among elderly people in 11 European populations. Journal of Epidemiology and Community Health 58(6):468-75.

IPUMS. 2015. Integrated Public Use Microdata Series: International Version 6.4 [Machine-readable database]. Minneapolis: Minnesota Population Center, University of Minnesota.

Kim, J., and E. Durden. 2007. Socioeconomic status and age trajectories of health. Social Science \& Medicine 65(12):2489-502.

Lovatón, R., D. Gondwe, A.S. McCarthy, P. Kirdruang, and U. Sharma. 2011. The Census Microdata Wealth Index: An application to predict education outcomes in developing countries. Proc. 58th World Statistical Congress, 2011, Dublin. Session CPS043. The Hague: International Statistical Institute.

Lynch, J., G.D. Smith, M. Hillemeier, M. Shaw, T. Raghunathan, and G. Kaplan. 2001. Income inequality, the psychosocial environment, and health: Comparisons of wealthy nations. The Lancet 358(9277):194-200.

Lynch, J., G.D. Smith, S.A. Harper, M. Hillemeier, N. Ross, G.A. Kaplan, and M. Wolfson. 2004. Is income inequality a determinant of population health? Part 1: A systematic review. Milbank Quarterly 82(1):5-99.

Lynch, S.M. 2003. Cohort and life-course patterns in the relationship between education and health: A hierarchical approach. Demography 40(2):309-31.

Mackenbach, J.P., A.E. Kunst, A.E. Cavelaars, F. Groenhof, J.J. Geurts, and EU Working Group on Socioeconomic Inequalities in Health. 1997. Socioeconomic inequalities in morbidity and mortality in Western Europe. The Lancet 349(9066):1655-59.

Mackenbach, J.P., V. Bos, O. Andersen, M. Cardano, G. Costa, S. Harding, [...], and A.E. Kunst. 2003. Widening socioeconomic inequalities in mortality in six Western European countries. International Journal of Epidemiology 32(5):830-37, https://doi.org/10.1093/ije/dyg209

Mackenbach, J.P., M. Huisman, O. Andersen, M. Bopp, J.K. Borgan, C. Borrell, [...], and C. Minder. 2004. Inequalities in lung cancer mortality by educational level in 10 European populations. European Journal of Cancer 40(1):126-35.

Marmot, M.G., and M.J. Shipley. 1996. Do socioeconomic differences in mortality persist after retirement? 25-year follow up of civil servants from the first Whitehall study. The BMJ 313(7066):1177-80.

Martelin, T. 1994. Mortality by indicators of socioeconomic status among the Finnish elderly. Social Science \& Medicine 38(9):1257-78.

Martikainen, P., P. Mäkelä, S. Koskinen, and T. Valkonen. 2001. Income differences in mortality: A register-based follow-up study of three million men and women. International Journal of Epidemiology 30(6): 1397-405.

McDonough, P., G.J. Duncan, D. Williams, and J. House. 1997. Income dynamics and adult mortality in the United States, 1972 through 1989. American Journal of Public Health 87(9):1476-83.

McMunn, A., J. Nazroo, and E. Breeze. 2009. Inequalities in health at older ages: A longitudinal investigation of the onset of illness and survival effects in England. Age and Ageing 38(2):181-87. 
Mirowsky, J., and C.E. Ross. 2008. Education and self-rated health cumulative advantage and its rising importance. Research on Aging 30(1):93-122.

Mishraa, G., K. Ball, A. Dobson, and J.E. Byles. 2004. Do socioeconomic gradients in women's health widen over time and with age? Social Science \& Medicine 58(9):1585-95.

Prus, S.G. 2007. Age, SES, and health: A population level analysis of health inequalities over the lifecourse. Sociology of Health \& Illness 29(2):275-96.

Ronsmans, C., and W.J. Graham (Lancet Maternal Survival Series Steering Group). 2006. Maternal mortality: Who, when, where, and why. The Lancet 368(9542):1189-200.

Ross, N.A., M.C. Wolfson, J.R. Dunn, J.M. Berthelot, G.A. Kaplan, and J.W. Lynch. 2000. Relation between income inequality and mortality in Canada and in the United States: Cross sectional assessment using census data and vital statistics. The BMJ 320(7239):898-902.

Rowlingson, K. 2011. Does Income Inequality Cause Health and Social Problems? Research Reports. York (UK): Joseph Rowntree Foundation. Available at https://www.jrf.org.uk/report/does-income-inequality-cause-health-andsocial-problems.

Sastry, N. 2004. Trends in socioeconomic inequalities in mortality in developing countries: The case of child survival in São Paulo, Brazil. Demography 41(3):443-64.

Say, L., and R. Raine. 2007. A systematic review of inequalities in the use of maternal health care in developing countries: Examining the scale of the problem and the importance of context. Bull World Health Organization 85(10):812-19.

Singh, G.K., and R.A. Hiatt. 2006. Trends and disparities in socioeconomic and behavioural characteristics, life expectancy, and cause-specific mortality of native-born and foreign-born populations in the United States, 1979-2003. International Journal of Epidemiology 35(4):903-19.

Singh, G.K., and M. Siahpush. 2001. All-cause and cause-specific mortality of immigrants and native born in the United States. American Journal of Public Health 91(3):392.

Stokoe, U. 1991. Determinants of maternal mortality in the developing world. Anz̧jog 31(1):8-16.

Subramanian, S.V., and I. Kawachi. 2004. Income inequality and health: What have we learned so far? Epidemiologic Reviews 26(1):78-91.

Timeaus, I. 1991. Measurement of adult mortality in less developed countries: A comparative review. Population Index 57:552-68.

Turrell, G., and C. Mathers. 2001. Socioeconomic inequalities in all-cause and specific-cause mortality in Australia: 1985-1987 and 1995-1997. International Journal of Epidemiology 30(2):231-39.

Victora, C., A. Wagstaff, S.J. Armstrong, D. Gwatkin, M. Claeson, and J.P. Habicht. 2003. Applying an equity lens to child health and mortality: More of the same is not enough. The Lancet 362(9379):233-41.

Vyass, S., and L. Kumaranayake. 2006. Constructing socio-economic status indices: How to use principal component analisys. Health Policy Plan 21(6):459-68.

Wagstaff, A. 2000. Socioeconomic inequalities in child mortality: Comparisons across nine developing countries. Bulletin of the World Health Organization 78(1):19-29.

Wagstaff, A., P. Paci, and E. Van Doorslaer. 1991. On the measurement of inequalities in health. Social Science \& Medicine 33(5):545-57.

Wilkinson, R.G., and K.E. Pickett. 2006. Income inequality and population health: A review and explanation of the evidence. Social Science \& Medicine 62(7):1768-84.

Willson, A.E., K.M. Shuey, and G.H. Elder, Jr. 2007. Cumulative advantage processes as mechanisms of inequality in life course health. American Journal of Sociology 112(6):1886-924. 